\title{
Analysis of WeChat Behavior of Chinese University Students
}

\author{
MAO Chen-lei1 \\ 'Jiangxi University of Technology, 330098 Nanchang, China
}

\section{Keywords: WeChat; University Student; Communication; New media}

\begin{abstract}
WeChat occupy more and more college students' media world. Equality, diversity, synchronization and other characteristics of WeChat accelerate its spread in Chinese university students. A variety of psychology elements of access to information, such as entertainment game, emotional communication, self image and maintain and expand the interpersonal relationship, establish the WeChat influence on university students.
\end{abstract}

\section{Introduction}

With the rapid development of intelligent mobile phone and other new media, the WeChat based on smart mobile phone platform become a common tool for university students' daily communication, according to incomplete statistics, the amount of WeChat users have more than 500 million, and the usage is very high, most of the users almost every day land WeChat platform. At present WeChat users are mainly young people, especially the university students, according to the survey, only $1.9 \%$ of the students had not heard of WeChat. WeChat, as a new communication medium, has an important influence on university students' life, including learning, interpersonal relationships, values and etc. We should give full play to WeChat as the carrier of Ideological education, strengthen university students' media literacy education, play WeChat's positive energy, and weaken its negative effects. The registered condition for WeChat is very low, only one mobile phone number or QQ number can be registered easily, so the user of WeChat are very complex. The impact and influence cannot be ignored. For curious students extremely, WeChat is a "double-edged sword", how to make good use of the sword, play the positive side and lowest the negative part.

In 1943, American psychologist Maslow put forward the basic theory of hierarchy of needs. The level of demand will be divided into 5 levels, the physiological need is in the bottom, and the need for direct living condition (such as food, water, air and sleep) and long-term survival (such as sexual needs) are important. Physiological need is biologically determined, and is the most primitive and basic need. The second level is the security need, including physical security and psychological security. The third level is the belongingness need, people is a social species, and the vast majority of people have a strong need to belong to a group. The fourth level is the esteem needs, including the esteem and respect from others. The last one is the self-actualization need, which is the development of individual potential, make oneself become the need that people want to be.

In modern society, the problem of food and clothing has been basically solved, especially for college students. School is relatively safe and simple environment, so the physiological need and safety need can be very easy to meet. However, for everyone, the inner feelings and thoughts on demand will need to solve by themselves. We live in an age of information explosion society, various types of information are all around us. But with the progress and development of the Internet, especially after entering the Web2.0 era, we are no longer passively to accept all kinds of 
information, we have the initiative to choose. In the "uses and gratifications communication theory": the audience will take the initiative to make choices about the contents of the dissemination. The audience is in an active role in the process of communication, because of the social and psychological needs, and led the media's expectations, in order to make a choice and contact, and finally met. With the emergence of new media, people can choose the more media, but whether it is television, newspapers, radio, WeChat or other new media, people are contacting the media based on their psychological needs, including the demand for information, entertainment, relax the mood and the demands of the demand of the interpersonal relationship and so on.

\section{Propagation characteristics of WeChat in the University}

Equality. The present communication target and living environment of university students determines the scope of interpersonal communication. In the survey, students' friends in the WeChat are mainly composed of classmates and friends, teachers and parents is the least proportion, so that the social circle is almost always with her in the same age, there is no special seniority rules of each other, but they have not yet entered society, no different workplace status of each other, so they are the relations of equality. Because of this equality, the circle of friends is simpler, the mutual exchanges between the main purposes is to contact the feelings, exchange ideas, learn knowledge, and discussion. Like this kind of relatively close hobby, age, social status in the society is defined as "peer group", they have the same background, especially the university students leave their parents to live independently, their frequent exchanges between the psychological identity to produce a higher sense of each other will have a great influence of formation and behavior consistent values and on this basis.

Synchronization. WeChat users can synchronize information dissemination, which ensure the timeliness of information exchange. A side sends a message, the other side will respond very quickly, the exchange and the reality of life in face-to-face communication is very similar, both sides of communication fluency greatly depends on the network conditions and user information transmission speed sometimes, the delay caused by the generation time may be an advantage, have more time to think about the reply message. Even if the other user is not online and cannot immediately receive the information, but when the user login, the delay of information will be the first time out, the timeliness of the message is still better than Email. WeChat ensures real-time and synchronization of remote information transmission, more low cost than the telephone communication, which has won more and more users, allowing users to be most willing to spend time on it. The propagation characteristics is the more obvious in the university student. Firstly, WeChat cost flow, and students have a wireless network in the campus and dormitory in many places, so its cost is relatively cheap. Secondly, compared to the working people, students' lives is very easy, leisure time is more, so they have more time to focus on the latest developments of WeChat, and can quickly respond to the information in the first time, which makes the communication more time synchronization.

Diversity. The external form and carrier of information is a symbol, which is a basic indispensable element of communication. In communication theory, human used sign will generally be divided into language symbols and non-language symbol, non-language symbols including gestures, facial expressions, action gestures and etc. In WeChat, interaction between people rely more on the symbolic interaction, sharing and exchange. WeChat still have text, voice, pictures, video, animation, expressions. It is important for now university students, because of the knowledge in the books will no longer be fully representative of a person ability, comprehensive strength is the 
most important, to understand all aspects of social knowledge and new information is one aspect of our comprehensive ability.

\section{Psychology of access to information}

Entertainment game. With the quickening pace of society, everyone has its own life stress, anxiety and most modern people, eager for quick success and instant benefit on interpersonal relationship and material income and lack a sense of security, which will affect the life and work of the state. Therefore, people began to search for a way of venting to relieve sense of anxiety due to too big pressure. Although university student has not faced the same worry and anxiety as social people, but in school they will also have their own troubles, freshman cannot adapt to the university campus, sophomore student has trouble because of much academic course pressure, Junior has confusion of future choice, Senior has anxiety for job, and graduate student has more pressure from the society. In a word, no matter in any environment and age, people will have different distress and anxiety. In the questionnaire, there are $69 \%$ students select "game, pass the boring time" as the reason for use of WeChat, and another $24 \%$ students in order to discharge pressure and relax. In WeChat, they can release all kinds of information, dynamic news, game, and interaction with others to increase the variety of knowledge, pass the boring time, meet the person's curiosity, to enjoy the hitherto unknown happiness, stress and depressive mood in the entertainment in the obtained relaxation, eliminate the worries of life and learning, so the fatigue of the day in which disappear from the scene.

Emotional communication. In this survey, there are up to $71 \%$ students to use WeChat with classmates and friends for contacts and exchanges. WeChat itself is a mobile phone chat software, its basic function is to send text, voice and multimedia messages. In the absence of the intelligent mobile phone, people contact with each other are on call, or send text messages, if the distance is far, call is not so convenient, it will be very expensive. But WeChat is without geographical restrictions and cheap rates, even in foreign countries, WeChat can be used as usual, but WeChat only cost flow, use any other functions do not charge a fee. Such features of WeChat also happens to meet the users in particular groups of students emotional communication needs, student has happy thing to share with friends immediately, and trouble thing can also find friends to vent. In addition, the WeChat provide closed private chat environment, which make it easier for people to express the usual ideas feel that shy to say by talking face to face or directly telephone communicate. Regular exchange and communication with people has the function of mental health care. People will seek to make their own physical and mental pleasure in nature, people in the process of communication to share each other's happiness, to share the pain, so as to obtain the sense of pleasure and intimacy, and everyone can get a sense of belonging in the process of communicating with others, and parents, lovers, friends is that they get from love and care.

Self image. People need to maintain themselves, to maintain their own sense of self value, increase self-esteem and respect for others on themselves. With the establishment of the development of the Internet and social networking sites, especially social networking tools such as WeChat, with the real name system, it directly copy the social reality to the virtual space, so the behavior of people in this virtual space has the same effect in real life, they also hope that through the self-identity in the process of interpersonal communication, so in order to obtain the approval of others. We must actively to express themselves, to shape the image of the self in the hearts of others. WeChat copy real life to the virtual reality space, but everyone in this space, the performance is not entirely true. In 
other words, WeChat like a small stage, in where people share text, pictures, video and so on as representative symbols of themselves, and then use these meet to shape the image in front of others.

Maintain and expand the interpersonal relationship. WeChat change the anonymous social networks, add friends from mobile phone communication with a high degree of credibility of the book and QQ friends. Based on the real name system, WeChat actually transfer the reality of social relations to the virtual space, breaking the barriers of real life and virtual network, provides a more convenient and trust between the individual and the individual space. In this space, the use of text and speech communication between individuals, circle of friends, the public account the sharing function to understand the dynamic information. A trust and familiarity with higher interpersonal relationship network gradually formed. In the school, because of the enclosed environment, university student has no more opportunities to come into contact with people in society, and WeChat multi-dimensional social just to meet their needs. They can make with their different age, different areas, different living environment, to further expand their interpersonal circle.

\section{Acknowledgment}

This work was supported by Jiangxi Province Office of Education of Humanities and Social Science Research [No. GL 1409]. The author thanks Dr. Hu Jian-feng for help.

\section{References}

[1] Alhabash, S., Park, H., Kononova, A., etc. (2012). Exploring the motivations of Facebook use in Taiwan. Cyberpsychology, Behavior, and Social Networking, 15, $304-311$.

[2] Balakrishnan, V. \& Shamim, A. (2013). Malaysian Facebookers: Motives and addictive behaviours unraveled. Computers in Human Behavior, 29, 1342 - 1349.

[3] Chen, G. M. (2011). Tweet this: A uses and gratifications perspective on how active Twitter use gratifies a need to connect with others. Computers in Human Behavior, 27, 755 - 762.

[4] Farooqi H, Patel H, Aslam H. M. etc. Effect of Facebook on the life of Medical University students. International Archives of Medicine 2013, 6:40

[5] Hong, F., Huang, D., Lin, H. etc. (2014). Analysis of the psychological traits, Facebook usage, and Facebook addiction model of Taiwanese university students. Telematics and Informatics,31, $597-606$.

[6] Kacvinsky L. E., Moreno M. A., (2014). Facebook Use between College Resident Advisors' and Their Residents: A Mixed Methods Approach, Coll Stud J. 48(1), 16 - 22.

[7] Koc, M. \& Gulyagci, S. (2013). Facebook addiction among Turkish college students: The role of psychological health, demographic, and usage characteristics. CyberPsychology, Behavior, and Social Networking, 16, $279-284$.

[8] Kuss, D. J., Griffiths, M. D., Karila, L. etc. (2014). Internet addiction: A systematic review of epidemiological research for the last decade. Current Pharmaceutical Design, 20, 4026 - 4052.

[9] Ryan, T., Chester, A., Reece, J. etc. (2014). The uses and abuses of Facebook: A review of Facebook addiction Journal of Behavioral Addictions 3(3), 133 - 148. 
[10]Cheung, C. M. K., Chiu, P. \& Lee, M. K. O. (2011). Online social networks: Why do students use Facebook? Computers in Human Behavior, 27, 1337-1343.

[11] Moreno M. A., Kota R., Schoohs S. etc. (2013). The Facebook Influence Model: A Concept Mapping Approach. Cyberpsychology, Behavior, and Social Networking, 16, 7. 